\title{
A categoria Video of the Year do VMA como construtora das convenções do videoclipe ${ }^{1}$
}

\section{The VMA's Video of the Year category as a definer of the music video conventions}

\section{Ariane Diniz Holzbach}

Professora adjunta de Estudos de Mídia da Universidade Federal Fluminense, doutora em Comunicação pela mesma universidade, com pós-doutorado em História pela Universidade Estadual do Rio de Janeiro (UERJ).

< arianeh@id.uff.br>

\section{RESUMO}

$\mathrm{O}$ artigo pretende compreender de que maneira uma categoria de premiação atua na consolidação das características estruturais do videoclipe. Para tanto, a proposta é analisar os 30 primeiros vencedores (1984-2014) da categoria Video of the Year, do Video Music Awards (VMA), a mais importante premiação do videoclipe, no intuito de perceber convenções que a premiação ajudou a consolidar. Como argumento central, considera-se que a categoria é um elemento fundamental do desenvolvimento do videoclipe especialmente em duas frentes: 1 ) ela potencializa que o videoclipe seja percebido como produto artístico e 2) ajuda a naturalizar características relacionadas à linguagem do gênero. Contudo, essa consolidação acontece através de variadas estratégias executadas pela MTV, criadora da premiação, visando a sua própria legitimação.

\begin{abstract}
The paper aims to understand how an award category operates in the consolidation of the structural features of the video clip. To do so, it analyzes the first 30 winners, from 1984 to 2014, of the most important award for video clips, the VMA's Video of the Year, in order to perceive the conventions that the award helps to consolidate. The central argument considers the Video of the Year category as a key element of video clip development, especially on two fronts: 1) it enhances the perception of video clip as an artistic product and 2) help to naturalize characteristics related to gender language. However, this consolidation takes place through various strategies implemented by MTV, creator of the award, aimed at its own legitimacy.
\end{abstract}

Keywords: Music video. Audiovisual. Communication

\section{Introdução}

Em 8 de agosto de 2011, para marcar os 30 anos da MTV, o jornalista Zeca Camargo elegeu eu seu blog os "30 melhores videoclipes da história" inspirado em uma matéria publicada pela revista Time. A escolha feita por ele é pessoal e, portanto, cheia de referências às experiências que vivenciou sobretudo como

1 Pesquisa financiada pela CAPES.

2 Texto disponível em: <http://goo.gl/fYq9Kt>. Acesso em: 19 nov. 2015. 
jornalista da MTV Brasil (1990-1994) e como profissional comumente vinculado à cultura pop. Uma rápida análise da lista suscita diversos questionamentos (o que, aliás, faz parte da experiência de fruição desse tipo de conteúdo): não há, por exemplo, nenhum videoclipe brasileiro, sequer latino-americano, nem nenhum exemplar oriental. O jornalista reproduziu um senso comum que insere os videoclipes anglo-saxões em um lugar diferenciado (e reverenciado) em relação aos demais. Mas o que faz com que esses videoclipes sejam supostamente "superiores"? Por que, em um mundo conectado em rede, ainda se consideram esses os "melhores"?

Além de incentivarem debates, as listas com os "melhores" servem a um papel social onipresente: a hierarquização cultural baseada numa noção pouco problematizada de qualidade. No caso do videoclipe, esse fenômeno é especialmente complexo, tendo em vista que ele se desenvolveu sendo observado à margem de outros produtos culturais, a exemplo da videoarte e do cinema, os quais seriam "mais" experimentais e artísticos. Não por acaso, a cultura do "melhor videoclipe" é incentivada há mais de 30 anos e foi fundamental para a sua consolidação como gênero audiovisual. Não há fã que não conheça o Video Music Awards (VMA), a mais famosa premiação dedicada ao videoclipe, e a sua principal categoria, o Video of the Year, que premia anualmente, desde 1984, "o melhor videoclipe do ano". Esta categoria é tão importante para a MTV, que criou o evento, e para a cultura do videoclipe que nunca foi extinta nem mudou de nome - diferentemente do que ocorreu com quase todas as demais - e costuma ter uma altíssima rotatividade, ou seja, raramente um mesmo artista recebe o prêmio mais de uma vez. O videoclipe vencedor, por sua vez, é transformado pelo evento em um exemplar que possui os atributos necessários a um "bom" videoclipe, a despeito de arrebatar o "grande prêmio" muitas vezes por critérios aparentemente políticos. O objetivo deste trabalho é entender de que maneira a categoria Video of the Year contribuiu para solidificar características que se transformaram em convenções da linguagem de videoclipe, atuando assim como um significativo construtor de critérios em torno da "qualidade" do gênero.

Para tanto, o trabalho está dividido em três partes. Na primeira, faremos uma reflexão em torno da construção social dos critérios de qualidade dos produtos culturais. Em seguida será feita uma rápida descrição das categorias do VMA, comparando-o com premiações análogas, como o Oscar e o Grammy, para então nos dedicarmos aos vencedores da categoria Video of the Year, de 1984 a 2014. Tendo em vista o número de ganhadores (30 vídeos), a análise não pretende ser totalizante; objetiva, diferentemente, utilizar esses vídeos como referências iniciais para se pensar na construção das convenções dos videoclipes. 


\section{A noção de qualidade dos produtos culturais}

Uma das características mais marcantes dos objetos culturais é a hierarquização que se faz socialmente das expressões artísticas e a oposição existente entre um certo conjunto de objetos, considerados "obras de arte", e um outro conjunto, considerado "comercial" e, portanto, menos arte. Para compreender esta complexa dicotomia, convém rememorar um dos mais importantes argumentos de Bourdieu (1996), para quem a legitimação da obra de arte vinculada ao aspecto econômico não pertence à natureza do objeto, mas desenvolveu-se historicamente, a partir de diversos fenômenos sociais. $\mathrm{O}$ autor considera que essa vinculação começou a ganhar contornos na Europa no século XVII, quando três expressões artísticas aparecem hierarquizadas: a poesia, o romance e o teatro. Enquanto este último era o que atingia maior público e lucro, a poesia era a expressão que atingia um público mais restrito. O prestígio dessas expressões, no entanto, era inversamente proporcional à quantidade de público e de lucro que atingiam: em primeiro lugar aparece a poesia, considerada a obra de arte de referência, em seguida o romance e, por último, o teatro. O juízo de valor construído socialmente das obras de arte, lembra Bourdieu (1996), já nessa época é condicionado a dois importantes fenômenos sociais: o julgamento dos pares e o sucesso comercial. A estratificação das classes sociais está no cerne dessa dicotomia, pois enquanto o grande número de analfabetos impedia que a poesia se tornasse uma expressão artística massificada, o teatro podia ser apreciado e compreendido pela maior parte das pessoas, mesmo que não tivessem uma educação formal. O romance aparecia no centro dessa tríade: não gozava do prestígio da poesia, mas era considerado uma arte "maior" que o teatro. A poesia, então, estabeleceu-se como a obra de arte da elite em contraposição ao teatro, tido como "popular".

No século XIX, essas diferenciações sofreram uma grande metamorfose. Apesar de a poesia ainda ser considerada a arte por excelência (embora atingisse um público cada vez mais reduzido), o teatro ganhou mais prestígio social em detrimento do romance, que passou a ser visto como mercantil, ligado ao jornalismo pelo folhetim. Percebe-se que mais um elemento relacionado ao aspecto econômico foi responsável por complexificar a valoração social desses objetos culturais: o crescimento da burguesia, que sanciona o teatro como a sua expressão artística de referência. O teatro, então, passa a ser visto como a grande obra de arte ao passo que o romance se transforma em algo "menor".

As obras que pertencem a cada gênero não são tratadas socialmente de forma homogênea, e, assim, no teatro, por exemplo, convivem peças com alto crédito social junto com peças consideradas menores, afinal, outros elementos 
precisam ser considerados para compreensão dessas valorações, como a busca pela distinção e o estabelecimento da autonomia artística. A principal forma de transformar uma obra de arte em algo distinto nessa época era criar estratégias para distanciar a obra do grande público, formado pelas classes populares. As obras experimentais, de "vanguarda", receberam crédito especial dos pares, ganhando assim maior legitimação artística que as obras "populares".

O estabelecimento da autonomia artística, por sua vez, ganhou forma no século XIX, quando os artistas passaram a viver em função da venda de suas obras. Além de Bourdieu, autores como Elias (1994) e Bakhtin (1998) percebem esse período como um momento fundamental de desenvolvimento da autonomia artística. Elias (1994), particularmente, tem em vista que a busca pelo sucesso comercial foi um dos grandes baluartes de desenvolvimento das artes nesse período. Bakhtin (1998), por sua vez, ao tratar do desenvolvimento do romance, coloca em discussão as metamorfoses sofridas por esse gênero literário no seio de uma sociedade moderna que, como tal, desenvolveu-se vinculada ao aspecto econômico-industrial.Quando a autonomia artística e os conflitos entre "arte" e "produto comercial" estão consolidadas, no século XX, os produtos engajados, reflexivos, edificantes e missionários são percebidos como "melhores" que os objetos voltados prioritariamente para o entretenimento ou "apenas" para a representação. Ficam excluídas, também, características consideradas exteriores à ordem política e intelectual, como a ênfase na emoção, na impressão e na espontaneidade. A obra de arte "de qualidade", portanto, precisa ser fruto de reflexão crítica e (aparente) dedicação. Nesse contexto, o aspecto econômico sofre um processo de ocultamento das obras de arte com maior prestígio social e, mais do que característica que serve de referência ao se observarem as expressões artísticas, a oposição estabelecida socialmente entre arte pura e arte comercial se naturaliza e passa a fazer parte da percepção dos produtos.

É possível, com isso, entender e problematizar o papel do videoclipe como obra de arte, visto que ele se construiu no extremo polo comercial da dicotomia "arte" versus "comércio". Desde seu cerne, no final da década de 1970, o videoclipe se estabeleceu como uma expressão vinculada explicitamente ao aspecto econômico, visto que surgiu primordialmente para vender 1) a imagem do artista e 2) a canção a qual se refere. Além disso, o seu desenvolvimento aparece desvinculado de um imaginário político, engajado ou intelectual. Embora exista um grupo significativo de videoclipes que tematize questões políticas, a sua função primordial é vender outro produto. Para isso, busca atrair o consumidor primeiramente pelo uso da emoção, de tal forma que está menos 
preocupado em contar uma história ou transmitir uma mensagem de teor político do que em fascinar, envolver as emoções do consumidor.

Mas como todas as expressões artísticas, o videoclipe sofre tensões em seu próprio campo. A partir dos anos de 1980, estabeleceram-se hierarquias que concedem a um determinado grupo de videoclipes a qualidade de "melhores", "mais arte" que outros. Essas tensões são responsáveis, inclusive, por uma mudança no olhar que se tem do gênero. No lugar de serem exclusivamente produtos para promover artistas e canções, alguns videoclipes passam a ser vistos como arte e ganham status diferenciado. Incluem-se aqui os que de alguma maneira se aproximam das obras de arte consolidadas, como a videoarte, e que têm no seu processo de produção a participação de artistas, diretores e músicos considerados "de vanguarda". Esse conflito no interior do gênero serve especialmente para intensificar a distinção construída entre o videoclipe "padrão", considerado comercial, e as obras de arte. As premiações relacionadas a ele, nesse contexto, servem a um duplo e conflituoso papel: de um lado, potencializam essa distinção ao se esforçarem para premiar o que consideram "de vanguarda". De outro lado, ao agirem dessa forma, as premiações transformam em convenção características dos vídeos que, em princípio, são percebidas como distintas, como será analisado a seguir.

\section{VMA e as categorias de premiação}

Desde que surgiu, o Video Music Awards (VMA) é a mais importante premiação dedicada ao videoclipe. Foi criado em 1984 pela MTV e, além de atrair audiência, foi desenvolvido para 1) legitimar a emissora como um espaço televisivo de vanguarda e 2) reforçar a percepção social de que o videoclipe seria, afinal, um produto artístico (Holzbach, 2013; 2014), o que legitimaria, novamente, a própria MTV, o único canal dedicado prioritariamente ao gênero na época. Tanto as categorias quanto os vencedores estimulam a delimitação de convenções que se transformam em referências de como o videoclipe deveria ser.

Convém destacar que, no decorrer do século $X X$, as premiações instituíram-se como fenômenos fundamentais de legitimação das expressões culturais percebidas como obras de arte (English, 2005; Watson e Anand, 2006). Esses eventos são carregados de aspectos simbólicos que objetivam sobretudo transformar os ganhadores em referências do bem-fazer artístico. Isso se dá especialmente por meio 1) do evento em si, que costuma desenvolver uma série de rituais (entrega do prêmio, votação dos pares, discurso do ganhador etc.) que ajudam a fixar os vencedores como obras de referência e 2) o desenvolvimento 
das categorias de premiação. Enquanto os rituais evidenciam o caráter subjetivo de construção dos cânones, as categorias chamam atenção para os aspectos concretos que a premiação julga importante na definição do que considera arte.

Desde a primeira edição, o VMA trabalha com um grande número de categorias, as quais demonstram uma aproximação como Oscar e como Grammy, as mais famosas premiações do cinema e da música, respectivamente. Essa vinculação atua como estratégia de legitimação do prêmio e, ao mesmo tempo, aproxima as convenções que definiriam o videoclipe como arte do cinema e da cultura musical considerados de referência. Enquanto uma série de categorias valorizam o artista e sua música - o que aponta para uma aproximação com o Grammy-, outras categorias valorizam aspectos técnicos e visuais do videoclipe - o que aproxima o VMA do Oscar. Da mesma forma que essas premiações, o VMA é bastante flexível, ou seja, extingue algumas categorias ao longo dos anos e cria outras, numa tentativa de adaptar o evento aos elementos textuais que são percebidos como importantes em cada momento. Na primeira edição do VMA, 16 categorias fizeram parte do evento. Totalizando todas as criadas até a edição de 2014, entretanto, tem-se 54 categorias.

A tabela 1 explicita a flexibilidade que o VMA se permitiu ao elaborar as categorias já que, em 30 anos, foram criadas novas categorias em 21 edições do evento. Na maior parte dos casos, o VMA criou uma ou duas ou fez adaptações nas já existentes; em alguns casos, no entanto, percebe-se a criação de um número maior de categorias, como ocorreu em 1989 e em 2007, o que indica importantes mudanças no evento em si e, quiçá, na percepção dos aspectos artísticos que o evento almeja conectar ao videoclipe. Em 1989, as novas categorias indicam uma aproximação entre o VMA e a indústria da música, dado que se concentram em premiar videoclipes ligados a diferentes gêneros musicais para além do rock, que representou o primeiro target da MTV originalmente (Banks, 1996; Goodwin, 1992). As categorias criadas em 2007, por sua vez, evidenciam uma questão diferente. Esse VMA foi o menor entre as 30 edições: fizeram parte da premiação apenas 11 categorias. Segundo jornais da época, isto teria acontecido em função da queda de audiência sofrida pela MTV nos anos anteriores. A opção da produção, por isso, seria fazer um evento pequeno, com baixos custos, e que explicitasse que a MTV estava aberta a conteúdos diferenciados que não dependessem demais do videoclipe. Após 2007, de fato, é notório o esforço do VMA em ampliar o hall de características a serem julgadas: há categorias para premiar trilhas sonoras de videogame e os 
lyric videos, que são os videoclipes comuns no YouTube feitos com a letra das canções.

\section{Tabela 1: Categorias que fazem ou fizeram parte do VMA ${ }^{3}(1984-2014)^{4}$}

\begin{tabular}{|c|c|}
\hline Video of the year (1984) & Best long form video (1991) \\
\hline Best male video (1984) & Best R\&B video (1993) \\
\hline Best female video (1984) & Best hard rock video (1996) \\
\hline Best group video (1984) & Best rock video (1997) \\
\hline Viewer's choice (1984) & Best pop video (1999) \\
\hline Best new artist (1984) & Best hip-hop video (1999) \\
\hline Best concept video (1984) & MTV2 Award (2001) \\
\hline Best stage performance (1984) & Best videogame soundtrack (2003) \\
\hline Best overall performance (1984) & Best videogame score (2006) \\
\hline Most experimental video (1984) & Male artist of the year (2007) \\
\hline Best direction (1984) & Female artist of the year (2007) \\
\hline Best choreography (1984) & Best group winner (2007) \\
\hline Best special effects (1984) & Most earth-shattering collaboration (2007) \\
\hline Best art direction (1984) & Monster single of the year (2007) \\
\hline Best editing (1984) & Quadruple threat of the year (2007) \\
\hline Best cinematography (1984) & Best dancing in a video (2008) \\
\hline Best video from film (1987) & $\begin{array}{l}\text { Best video (that should have won a Moonman) } \\
\qquad(2009)\end{array}$ \\
\hline Breakthrough video (1988) & Best collaboration (2010) \\
\hline Best rap video (1989) & Best dance music video (2010) \\
\hline Best dance video (1989) & Best breakthrough video (2010) \\
\hline Best heavy metal video (1989) & Best video with a message (2011) \\
\hline Best postmodern video (1989) & Best electronic music video (2012) \\
\hline Best metal/hard rock (1990) & Most share-worthy video (2012) \\
\hline Video vanguard award (1990) & Best latino artist (2012) \\
\hline Best alternative video (1991) & Best visual effect (2012) \\
\hline Artist to Watch (2013) & Best Song of the Summer (2013) \\
\hline Best Lyric Video (2014) & MTV Clubland Ward (2014) \\
\hline
\end{tabular}

Fonte: Página oficial do VMA

3 As informações referentes a todos os vencedores do VMA foram retiradas da página oficial do VMA: Disponível em: http://www.mtv.com/ontv/vma/. Acesso em: 19 nov. 2015.

4 Entre parênteses, o ano de criação da categoria. 
Mais do que instituir o exemplar vencedor como obra de arte, portanto, o Video of the Year serve como um agregador simbólico do que, paulatinamente, o VMA instituiu como "qualidade", como será analisado a seguir. Para fins metodológicos, as edições do evento foram divididas cronologicamente em quatro partes. Em cada intervalo é possível perceber mudanças significativas nos objetivos do Video of the Year.

\section{4-1988: A valoração da MTV e dos aspectos visuais e do videoclipe}

Os primeiros ganhadores do Video of the Year são sintomáticos em relação aos objetivos da MTV ao criar o VMA, visto que, mais do que apresentarem aspectos técnicos do que a emissora considera como "qualidade", os vencedores explicitam, também, uma tentativa de definição da identidade do canal.

O primeiro vencedor é significativo nesse sentido. Embora a primeira edição do evento tenha ocorrido no mesmo ano de popularização de Thriller, certamente o videoclipe mais importante para legitimação do gênero até hoje, ele não foi o vencedor desta categoria, embora tenha sido finalista. Para inaugurar o VMA, a MTV escolheu um videoclipe que sintetizou ao máximo a identidade do canal musical: You Might Think, do grupo de rock estadunidense The Cars. O trabalho foi dirigido por Jeff Stein, Alex Weil e Charlie Levi e possui um elemento caro à MTV: o bom humor. A letra é uma declaração de amor na qual o cantor afirma que a moça por quem é apaixonado deve pensar que ele é louco por querer ficar tanto ao lado dela. O videoclipe monta várias situações nas quais o vocalista do The Cars, Ric Ocasek, aparece nos lugares mais inusitados, surpreendendo a mulher por quem estaria apaixonado.

Figura 1: Frames de You Might Think
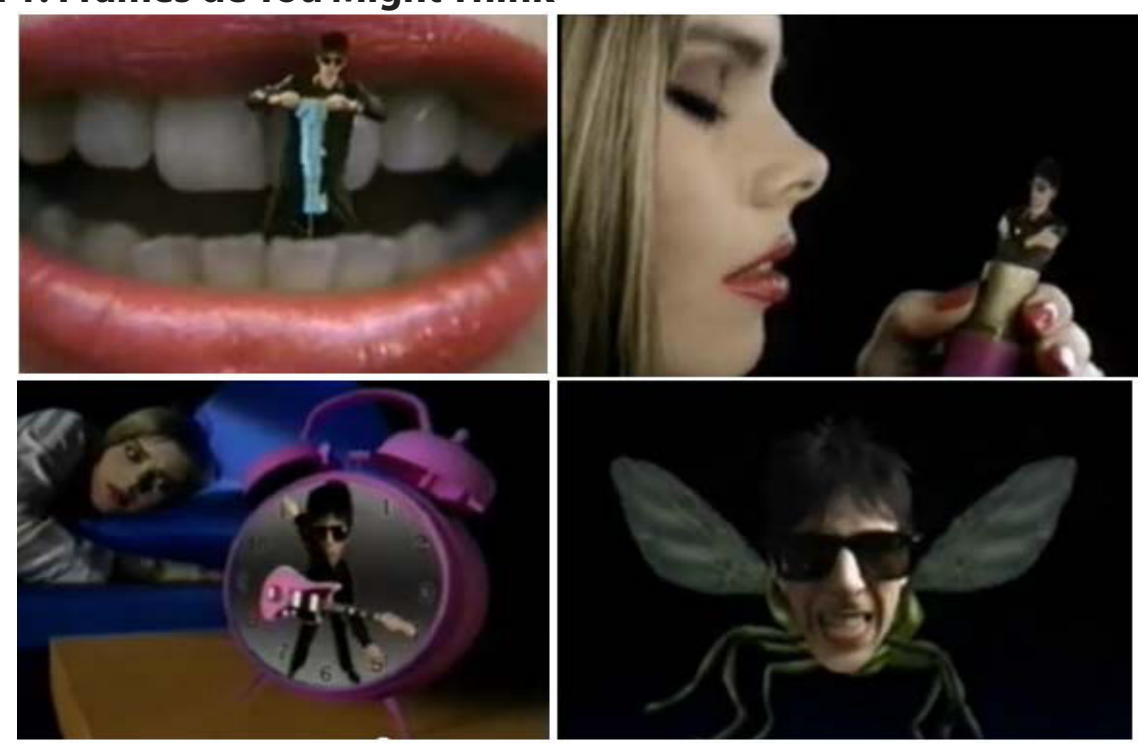
O bom humor foi construído a partir de técnicas de computação gráfica pouco usuais até então, o que concede ao videoclipe um caráter experimental. Ele faz também uma sintomática referência ao cinema quando, no meio do vídeo, Ric Ocasek aparece com formas de gigante e escalando o Empire State Building, em Nova York, em referência ao filme King Kong, clássico do cinema hollywoodiano. As imagens irreverentes e a referência ao cinema juntam-se a um terceiro elemento: a presença dos artistas desenvolvendo algum tipo de performance musical. Uma das convenções mais usuais no videoclipe é a presença quase obrigatória dos músicos em cena, seja interpretando a música, seja tocando instrumentos, seja desenvolvendo coreografias. Na maioria dos casos, os músicos simulam uma performance através, por exemplo, da realização de playback. Essa encenação, embora reconhecida e aceita na experiência de fruição do videoclipe, transgride uma importante convenção de alguns gêneros musicais como o rock, os quais valorizam o "ao vivo" como um quesito necessário da performance presencial (Frith, 1996).

Em 1985, na segunda edição do VMA, o vencedor do Video of the Year foi The Boys of Summer, do texano Don Henley, ex-vocalista da influente banda de rock Eagles. A letra explora os amores efêmeros, mas afirma que o amor de quem canta a canção é eterno e a mulher amada, por sua vez, descobriria isso quando "os amores de verão forem embora". O videoclipe foi dirigido pelo francês Jean-Baptiste Mondino, que também é fotógrafo e, por isso, explorou diversas características da fotografia nas imagens desse videoclipe. O trabalho é todo em preto e branco e intercala imagens da performance musical de Don Henley com imagens sensuais relacionadas à diversão da juventude no Verão.

Figura 2: Frames de The Boys of Summer

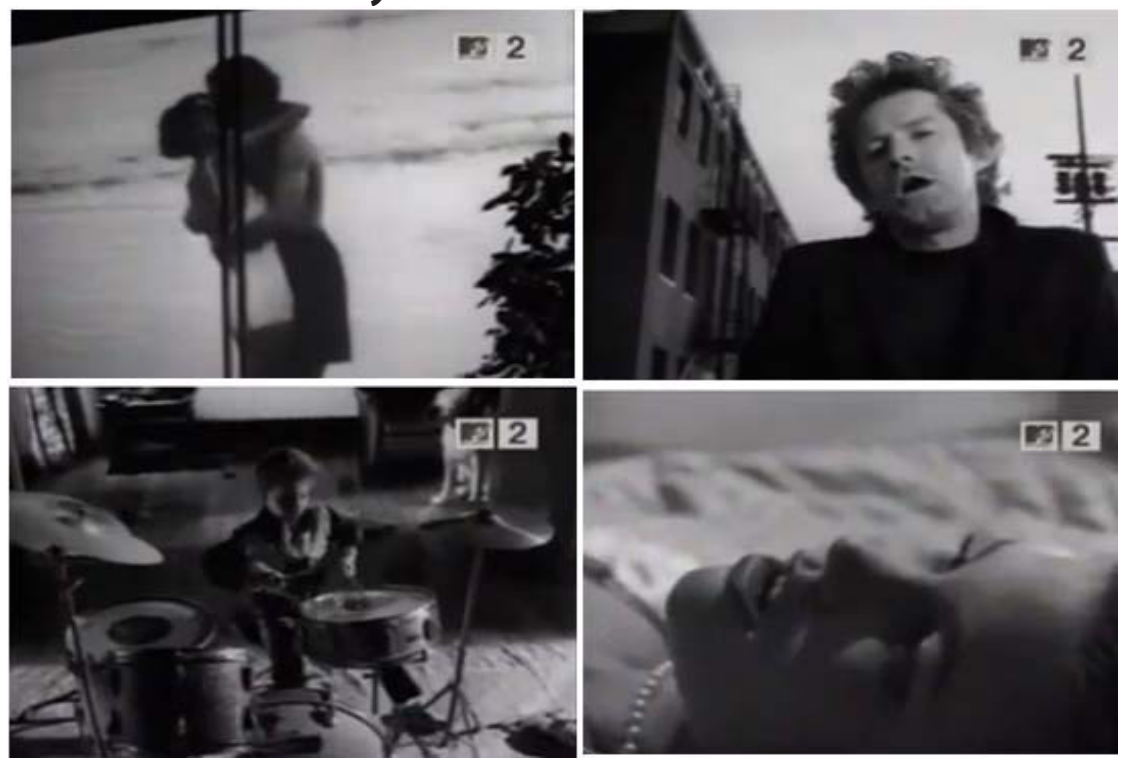


A lírica narrativa visual transformou o diretor em um dos mais celebrados da cultura do videoclipe. Foi Mondino quem, cinco anos mais tarde, dirigiu Justify My Love, de Madonna, um dos mais polêmicos da cantora, mas também um dos mais aclamados, em função do apelo sexual. Como em The Boys of Summer, o videoclipe é em preto e branco entrecortado por imagens sensuais, o que aponta para a consolidação dessa estética na cultura do videoclipe. 0 cuidado com a fotografia - feita em geral para (super)valorizar habilidades e características físicas dos cantores - e a ousadia imagética transformaramse em importantes marcas do videoclipe. Para tanto, o cuidado excepcional com aspectos técnicos como a iluminação concedem certo caráter idílico aos cantores e demais elementos em cena. Esses aspectos são especificamente valorizados em outras categorias do VMA, como a Best Cinematography, o que acabou servindo de pretexto a mais para serem desenvolvidos na cultura do videoclipe.

A categoria Video of the Year reforçou ainda elementos para além dos aspectos técnicos do videoclipe. Em 1986, o vencedor foi Money for Nothing, da banda britânica Dire Straits. Como acontece em You Might Think, utiliza recursos de computação gráfica e foi considerado, por isso, inovador. Seu conteúdo expõe a performance dos músicos no palco entrecortada por imagens redundantes em relação à letra, além da onipresença da MTV tanto na letra - em estrofes como "I want my MTV" - quanto nas imagens. A ânsia em valorizar os músicos (e, num certo sentido, a própria MTV) estimulou este videoclipe a inaugurar uma nova etapa da categoria Video of the Year expressivamente voltada para a experimentação imagética. A presença desse elemento se repetiu em 1987, quando Sledgehammer, do britânico Peter Gabriel, foi o Video of the Year. Até hoje, este é um dos videoclipes mais importantes da MTV e da carreira de Peter Gabriel especialmente em função do seu caráter imagético-experimental.

Nem sempre, contudo, a performance musical aparece como elemento complementar a uma história qualquer no videoclipe. Em muitos casos, ela é o principal e às vezes o único elemento imagético presente. A performance musical ganhou status de protagonista em Need You Tonight/Mediate, do grupo INXS, em 1988. O título do videoclipe é inusitado porque reúne duas músicas da banda - Need You Tonight and Mediate - , as quais, de maneira bastante incomum, protagonizam um mesmo videoclipe. Este, dirigido por Richard Lowenstein, é igualmente dividido em duas partes. A primeira utiliza a música Need You Tonight e é inteiramente formada pela performance dos músicos, aos moldes do que fariam em apresentações ao vivo. O vocalista Michael Hutchence interpreta a canção em playback encarando a câmera e dança, rodopia e salta em imagens 
que por vezes são coloridas e por vezes são em preto e branco, estimulando, inclusive, uma grande flexibilidade no uso da fotografia no videoclipe.

A segunda parte do vídeo, que tem a música Mediate como base, resolve uma importante questão para a MTV: ela concede um passado à história do videoclipe. É possível apontar indícios do nascimento do gênero ainda na década de 1960, quando grupos como os Beatles gravaram cenas de suas performances ao vivo e as transmitiram na televisão. Todavia, foi apenas com o surgimento e a consolidação da MTV que o videoclipe passou a ser um produto relevante e necessário para a indústria da música e, também, para a própria televisão. Mediate faz referência a Subterranean Homesick Blues, de Bob Dylan, feito em 1965, pelo menos 16 anos antes da estreia da MTV. Embora seja comumente tratado como um videoclipe, o vídeo é na verdade a sequência de abertura do documentário Don't Look Back, dirigido por D. A. Pennebaker, que estreou em 1967 e cobriu a turnê que Dylan havia feito em 1965 no Reino Unido. A importância dessa sequência de abertura é patente na cultura do videoclipe, pois se tornou uma referência sistematicamente citada ao ser descrita a história do gênero. Em Subterranean Homesick Blues, Bob Dylan vai deixando cair no chão cartazes que contêm partes da letra da música no momento em que a canção as profere (seria um precursor dos lyric videos?). Em Mediate, o INXS faz o mesmo. A referência que a banda australiana constrói em torno de uma das canções mais famosas de Dylan é um elemento de valorização do próprio videoclipe como produto cultural, além de explicitar que o gênero tem uma história e um passado, o que concede raízes a ele. Ao premiar este videoclipe com a principal estatueta do VMA, a MTV esclarece que o seu mais valioso conteúdo é anterior à sua própria existência.

[ Figura 3: À esquerda, frame de Need You Tonight/Mediate. À direita, Subterranean Homesick Blues
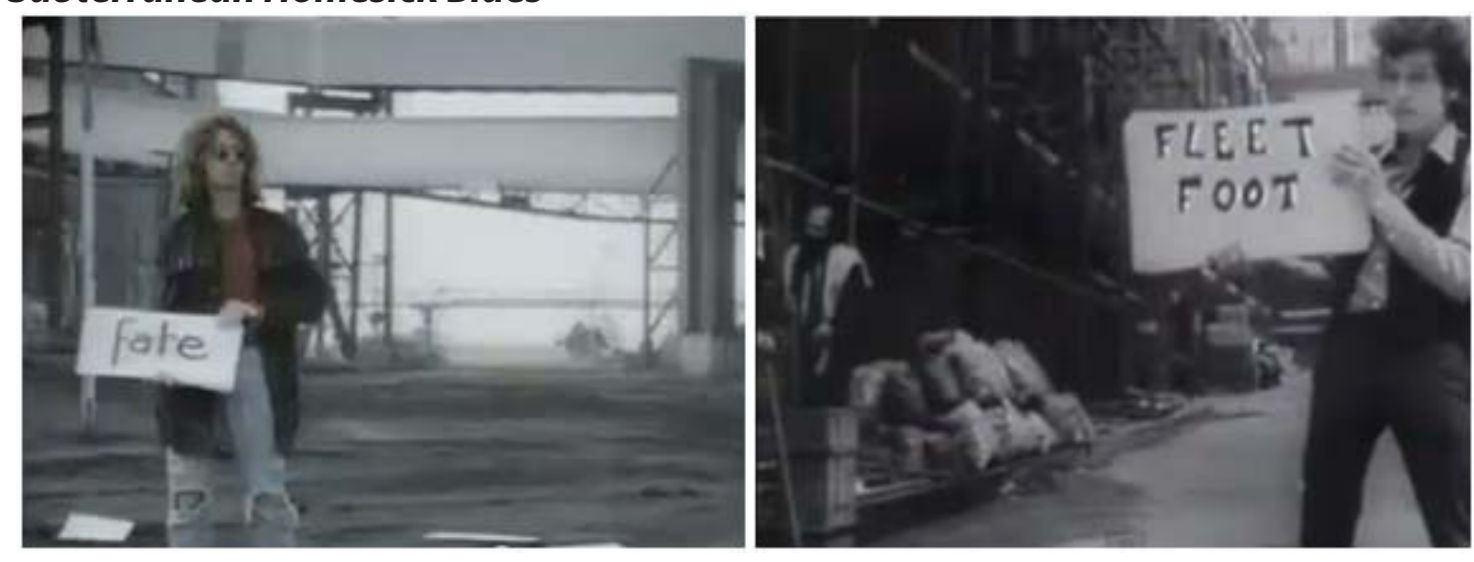


\section{9-1994: Video of the Year e valoração do aspecto musical do videoclipe}

Como apontam diversos autores (Banks, 1996; Denisoff, 1988; Goodwin, 1992; Kaplan, 1987), a MTV construiu sua identidade inicial como um canal dedicado ao rock. Os primeiros vencedores do Video of the Year, por isso, refletiram o target da emissora. A partir de 1989, contudo, numa clara tentativa de ampliação de conteúdo e de público, o VMA começou a criar categorias relacionadas aos gêneros musicais, os quais já vinham sendo veiculados há algum tempo na programação da emissora. Essa mudança causou reflexos na categoria Video of the Year, que passou a ser um termômetro de aferição de variados gêneros musicais trabalhados no canal. Essa mudança, contudo, não aconteceu de um ano para o outro. Entre 1989 e 1994, quando o VMA já havia criado diversas categorias voltadas para diferentes gêneros musicais, a categoria Video of the Year continuou premiando exclusivamente videoclipes de grupos ou artistas comumente relacionados ao rock. Os vencedores desse período foram:

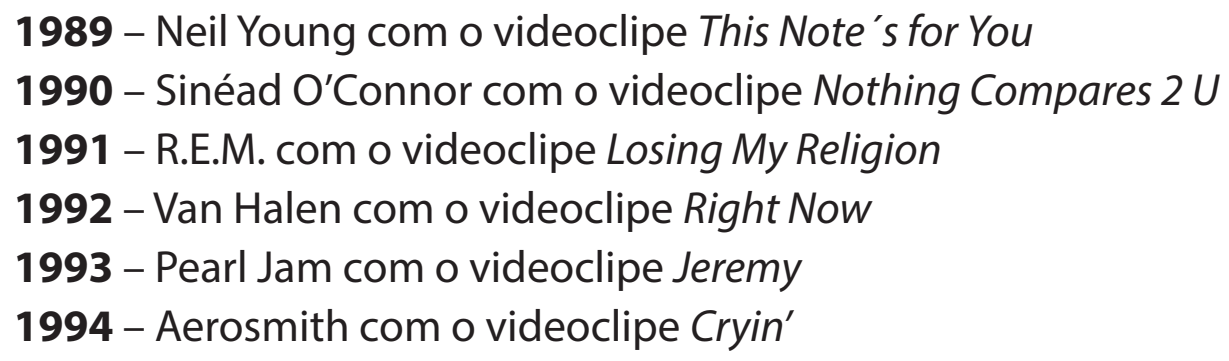

1989 - Neil Young com o videoclipe This Note's for You

1990 - Sinéad O'Connor com o videoclipe Nothing Compares $2 U$

1991 - R.E.M. com o videoclipe Losing My Religion

1992 - Van Halen com o videoclipe Right Now

1993 - Pearl Jam com o videoclipe Jeremy

1994 - Aerosmith com o videoclipe Cryin'

A manutenção do que parecia ser a tradição rock pelo máximo de tempo possível significou o desenvolvimento de uma estratégia da própria MTV para não ser percebida como musicalmente em crise ou numa radical fase de mudança de target, já que enquanto a principal categoria do VMA valorizava exclusivamente o rock, a MTV podia se considerar, afinal, uma emissora de rock. Os videoclipes que venceram a categoria até 1994, da mesma maneira, continuaram enfatizando o bom humor (This Note's for You), a experimentação (Losing My Religion e Right Now) e a performance dos músicos (Nothing Compares 2 U, Jeremy e Cryin').

Adicionalmente, alguns elementos inspirados na cultura do cinema foram ainda mais valorizados, como ilustra o caso de Cryin', da banda Aerosmith. Esse videoclipe narra a história de uma adolescente traída pelo namorado que, ensandecida, sai pela cidade fazendo pequenas loucuras, como colocar um piercing no umbigo. Após o lançamento desse vídeo, mais dois foram produzidos 
a partir de singles do Aerosmith - Amazing e Crazy - formando uma trilogia. Os três videoclipes foram lançados entre 1993 e 1994 como parte do álbum Get a Grip, foram dirigidos pelo mesmo diretor, Marty Callner, e foram protagonizados pela mesma atriz, Alicia Silverstone.

\section{5-2006: o Video of the Year para além do rock}

A categoria Video of the Year começou a premiar novos gêneros musicais em 1995, quando o trio TLC venceu com Waterfalls. Além de ter sido a segunda vez que um artista (no caso, um trio) do sexo feminino ganhara este prêmio - a primeira fora em 1990 com Sinéad O'Connor - o destaque desse ano é evidente por causa do gênero musical que o TLC integra. O grupo, formado por três mulheres, costuma ser vinculado ao R\&B e ao hip hop - jamais ao rock. O seu principal atrativo visual não passa por uma performance de palco aos moldes do que fazem as bandas de rock. Diversos de seus videoclipes exploram a imagem bonita das três integrantes e o modo como dançam. O videoclipe Waterfalls, primeiramente, explora a coreografia dançada sensualmente pelo TLC. Em segundo lugar, utiliza um recurso já consolidado anteriormente: uma história se desenvolve entrecortada pela performance coreografada do grupo.

- Figura 4: Frames de Waterfalls, dirigido por F. Gary Gray

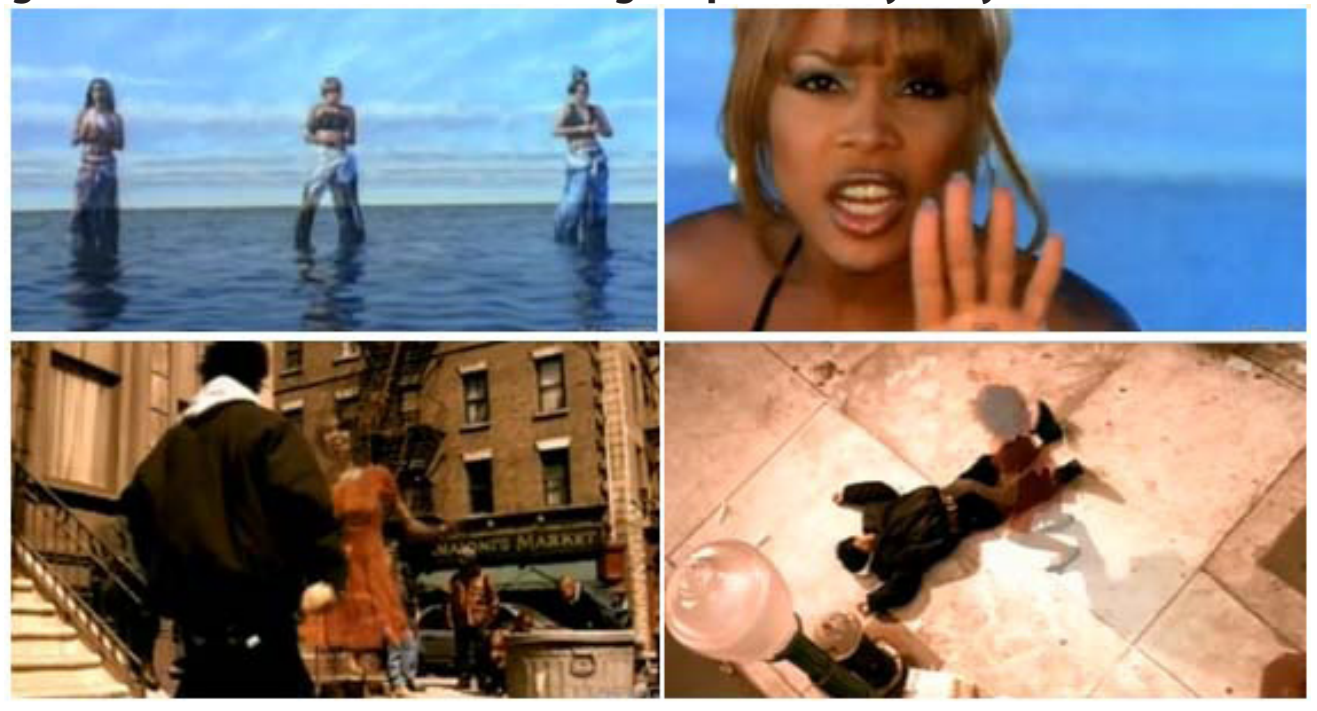

Sem diálogos ou qualquer elemento sonoro além da música, a história contada em Waterfalls narra duas situações. A primeira dá conta de um adolescente pobre, que trabalha como traficante de drogas contra a vontade da mãe e acaba assassinado por outros traficantes. A segunda história acontece 
entre um casal de jovens que transa sem proteção e, por causa disso, um deles transmite aids para o outro. A história violenta contrasta com o azul do céu e do mar que permeia as partes nas quais o TLC aparece dançando e colorindo o vídeo, naturalizando mais uma vez uma estrutura que se tornou comum no videoclipe: uma história narrativizada entrecortada pela performance do artista. Em Waterfalls, essa estrutura é particularmente complexa, pois dá conta de duas histórias com início, meio e fim, além da presença constante das três integrantes do grupo dançando e cantando, e tudo acontecendo em apenas cinco minutos e 15 segundos. Do ponto de vista temático, o tom moralizante do vídeo - uso de drogas e sexo sem proteção são errados - certamente pesou para ele ser o Video of the Year de 1995. No entanto, a escolha significa muito mais, tendo em vista que acabou com a hegemonia do rock no VMA, gênero que a partir de então foi sistematicamente perdendo espaço na principal categoria da premiação.

Essa mudança no que a MTV havia construído desde $1^{\circ}$ de agosto de 1981, quando estreou, tem como causa uma radical mudança no papel da emissora como o lugar do videoclipe e, também, na relação mantida com as grandes gravadoras e com as mídias hegemônicas voltadas para música. A opção da MTV em voltar, inicialmente, sua identidade para o rock foi uma estratégia desenvolvida para atrair a audiência jovem que não tinha muitas escolhas na televisão broadcasting e na TV a cabo. A novidade que a emissora representou foi causada especialmente pelo fato do jovem desconhecer a maior parte das músicas que o canal veiculou em seu início (Goodwin, 1992). Em 1995, esse papel alternativo desempenhado pela MTV não mais existia. A emissora então se viu obrigada a se adaptar às mudanças ocorridas na cultura musical.

Embora Waterfalls seja emblemático em relação à metamorfose musical sofrida pela MTV, a categoria Video of the Year mostra que o VMA realizou essa mudança lentamente, de forma a tentar manter parte da identidade rock vigente até então. Depois de 1995 e até 2006, a categoria Video of the Year ainda contemplou o rock em quatro ocasiões:

1996 - Smashing Pumpkins com o videoclipe Tonight, Tonight
1997 - Jamiroquai com o videoclipe Virtual Insanity
2005 - Green Day com o videoclipe Boulevard of Broken Dreams
$\mathbf{2 0 0 6}$ - Panic! At the Disco com o videoclipe I Write Sins Not Tragedies

Os quatro vencedores exploram a performance das bandas. Todavia, no lugar de apresentarem os integrantes tocando seus instrumentos, eles expõem as bandas "inseridas" nas temáticas dos vídeos, como se fossem atores além 
de músicos. Esta estrutura explora o apelo visual (e teatral) que os músicos apresentam em detrimento de suas habilidades como músicos. Ademais, esses videoclipes expõem os vocalistas interpretando a canção e, contrariamente, concedem um papel secundário aos demais integrantes das bandas. Em alguns casos (como em Virtual Insanity), a banda nem sequer aparece no vídeo, apenas o vocalista, concedendo com isso um valor exponencialmente maior a quem canta a canção. Os demais vencedores da categoria Video of the Year potencializaram o espaço concedido às performances mais teatrais e coreografadas. Abaixo está a lista dos demais vencedores até 2004, na qual fica nítida a ênfase concedida pela MTV à black music, com destaque para o R\&B, o hip hop e o rap.

1998 - Madonna com o videoclipe Ray of Light - pop

1999 - Lauryn Hill com o videoclipe That Thing - R\&B, hip hop

2000 - Eminem com o videoclipe The Real Slim Shady - rap

2001 - Christina Aguilera, Lil'Kim, Mya, P!inke Missy Elliot com o videoclipe Lady Marmalade - pop

2002 - Eminem com o videoclipe Without Me - rap

2003 - Missy Elliot com o videoclipe Work It - hip hop

2004 - Outkast com o videoclipe Hey Ya! - hip hop

Ao conceder ênfase a gêneros para além do rock, a categoria Video of the Year ajudou a consolidar componentes da cultura do videoclipe que não tinham tanto espaço, até então, na premiação. Apenas nesse momento, por exemplo, o VMA teve abertura para premiar artistas que há muito faziam sucesso na MTV, como Madonna, que venceu a categoria só em 1998 com Ray of Light, mas esteve presente no VMA desde a primeira edição, quando desenvolveu a famosa performance de Like a Virgin vestida com um vestido de noiva.

\section{7-2014: O Video of the Year na era da internet}

A partir de 2007, a categoria Video of the Year sentenciou 1) o fim definitivo da identidade rock construída pela MTV e 2) a valorização de videoclipes popularizados em espaços multiplataforma. Todos os videoclipes premiados entre 2007 e 2014 se distanciam do rock e se popularizaram em sites de compartilhamento de vídeos, como o YouTube. Como apontam Burgess e Green (2009), embora criado em 2005 para compartilhar conteúdo amador, o YouTube em pouco tempo se transformou, também, em um repositório fundamental de conteúdo institucional. O videoclipe encontrou um espaço promissor nesse site, a ponto de, atualmente, ser um de seus conteúdos mais consumidos. OYouTube 
ajudou o videoclipe a se tornar independente da televisão e a categoria Video of the Year refletiu de variadas maneiras esse novo comportamento do gênero. Os vencedores desse período foram:

2007 - Rihanna e Jay-Z com o videoclipe Umbrella

2008 - Britney Spears com o videoclipe Peace of Me

2009 - Beyoncé com o videoclipe Single Ladies

2010 - Lady Gaga com o videoclipe Bad Romance

2011 - Katy Perry com o videoclipe Firework

2012 - Rihanna e Calvin Harris com o videoclipe We found love

2013 - Justin Timbarlake com o videoclipe Mirrors

2014 - Miley Cyrus com o videoclipe Wrecking Ball

A partir de 2007, todos os vencedores costumam ser enquadrados no gênero pop e atingiram um alto número de visualizações no YouTube antes mesmo de vencerem a principal categoria do VMA. O videoclipe Single Ladies (dirigido por Jake Nava), por exemplo, que ultrapassa os 440 milhões de visualizações no site, foi desenvolvido com objetivo de ser espraiado na Internet. Apostando no engajamento da cultura fã, a cantora Beyoncé desenvolve uma complexa coreografia que incentivou centenas de milhares de internautas a reproduzirem a dança e publicarem o resultado no YouTube, em um expressivo caso de cultura participativa que teve o videoclipe como mola propulsora. Ele também fez parte, por exemplo, do processo de celebrificação da cantora de forró Stefhany, em 2009 (Lisenberg, 2012), e da reprodução de um sem-número de spoofs, como aponta Fernandes Junior (2012). Um engajamento parecido pode ser observado a partir do videoclipe Bad Romance, dirigido por Francis Lawrence, e Wrecking Ball, dirigido por Terry Richardson.

A linguagem visual de todos esses vencedores trabalha convenções já solidificadas em anos anteriores, como a interpretação encenada da letra feita pelo cantor (em todos os casos), a presença da coreografia (todos, com exceção de Firework), uma ou algumas histórias entrecortadas pela performance musical (Firework, We found lovee Mirrors) e o cuidado extremo com a fotografia (Umbrella, Bad Romance, We Found Love e Mirrors). A experimentação imagética, nesse período, sofreu uma radical exclusão talvez como reflexo da supervalorização da performance musical, um elemento que parece incentivar a participação dos internautas na confecção de suas próprias produções. A partir de 2007, assim, a categoria Video of the Year explicita que a MTV e o próprio VMA vêm atuando 
como reprodutores de uma cultura do videoclipe que está se desenvolvendo na internet, não mais na televisão tradicional.

\section{Considerações finais}

A escolha do Video of the Year do Video Music Awards é muito mais do que a categoria da mais importante premiação do videoclipe. A análise dos vídeos vencedores demonstra que ela serve como uma janela de observação para se perceber uma série de questões em torno da legitimação do videoclipe percebido como arte e da maneira como a MTV desenvolveu estratégias de legitimação, de definição de conteúdo e, consequentemente, de público que almejava atingir.

Considerando que o VMA acompanhou a popularização do videoclipe e a definição das suas convenções textuais, é possível ter em vista que a categoria Video of the Year vem atuando como um importantíssimo lugar de celebração do que se torna referência do videoclipe "de qualidade", o que foi fundamental para a sua consolidação como gênero. Do ponto de vista estrutural, a categoria explicita a solidificação de diversas convenções, a exemplo da presença do vocalista interpretando a canção, da existência usual de uma narrativa visual entrecortada pela performance dos cantores, da valorização da fotografia e da experimentação imagética, do desenvolvimento de coreografias e da necessidade cada vez mais premente de os grupos musicais agirem como atores, além de músicos.

Do ponto de vista do conteúdo dos videoclipes, a análise mostrou que, inicialmente, o VMA valorizou videoclipes comumente ligados ao rock, mas, a partir de 1989, ampliou os gêneros musicais presentes, incluindo, por exemplo, premiações para videoclipes de hip hop e de pop. Esta flexibilização só alcançou a categoria Video of the Year, todavia, em 1995, quando paradigmaticamente o grupo TLC foi o vencedor com Waterfalls. A partir de então, a principal categoria do VMA foi constantemente aumentando a valorização de outros gêneros para além do rock. A partir de 2007, o distanciamento com esse gênero estava plenamente instaurado, o que refletiu uma grande mudança no conteúdo geral do canal e, também, no público que ele almejava atingir a partir de então. Ademais, a partir de 2007, ficou patente a relação que a premiação passou a travar com a internet. Ao agir assim, a MTV explicitou que não mais é responsável pela popularização do videoclipe como gênero. Este, por sua vez, se tornou independente da televisão e encontrou seu espaço de ascensão na internet, o que exige que seja percebido de uma nova perspectiva, talvez ainda mais desafiadora. 


\section{Referências}

BAKHTIN, Mikhail. Questões de Literatura e de Estética: A Teoria do Romance. São Paulo: Editora UNESP, 1998.

BANKS, Jack. Monopoly Television: MTV's Quest to Control the Music. Colorado: Westview Press, 1996.

BOURDIEU, Pierre. As Regras da Arte: gênese e estrutura do campo literário. Lisboa: Presença, 1996.

BURGESS, Jean; GREEN, Joshua. YouTube e a revolução digital: Como o maior fenômeno da cultura participativa está transformando a mídia e a sociedade. São Paulo: Aleph, 2009.

DENISOFF, R. Serge. Inside MTV. New Brunswick: Transaction Publishers, 1988.

ELIAS, Norbert. Mozart: Sociologia de um Gênio. Rio de Janeiro: Zahar, 1994.

ENGLISH, James. The Economy of Prestige: Prizes, Awards, and The Circulation of Cultural Value. Cambridge: Harvard University Press, 2005. Disponível em: < http://dx.doi.org/10.4159/9780674036536>. Acesso em: 23 nov. 2015.

FERNANDES JUNIOR, Aroldo Santos. Eu Venho Perdendo Você: O Desaparecimento nos Vídeos-Performance "Madimoizele Gessyu - Sorte" e "Single Man Dances to Single Ladies". Revista Gambiarra, Rio de Janeiro, n. 4, p. 15-21, 2012.

FRITH, Simon. Performing Rites: on the value of popular music. Cambridge/ Massachusetts: Harvard University Press, 1996.

GOODWIN, Andrew. Dancing in the Distraction Factory: Music Television and Popular Music. Minneapolis: University of Minnesota Press, 1992.

HOLZBACH, Ariane Diniz. Smells Like Teen Spirit: a consolidação do videoclipe como gênero áudio-visual. Tese (Doutorado em Comunicação Social). Programa de Pós-graduação em Comunicação da Universidade Federal Fluminense, Rio de Janeiro, 2013.

. O Video Music Awards e a consolidação do videoclipe como gênero. Revista Fronteiras, São Leopoldo, v. 16, n. 2, p. 91-103, maio/agosto 2014. Disponível em: <http://goo.gl/nINbYF>. Acesso em: 9 jun. 2016.

KAPLAN, Elizabeth Ann. Rocking Around The Clock: Music Television, Postmodernism and Consumer Culture. London: Methuen, 1987.

LIESENBERG, Susan. O processo de celebrificação na internet: O caso de Stefhany do Crossfox. Dissertação (Mestrado em Comunicação e Informação). Programa de Pós-graduação em Comunicação e Informação, Universidade Federal do Rio 
Grande do Sul (UFRGS), Porto Alegre, 2012.

WATSON, Mary; ANAND, N. Award ceremony as an arbiter of commerce and canon in the popular music industry. Popular Music, Cambridge, v. 25, n. 1, p. 41-52, jan. 2006. Disponível em: <http://dx.doi.org/10.1017/S0261143005000747>. Acesso em: 10 jun. 2016.

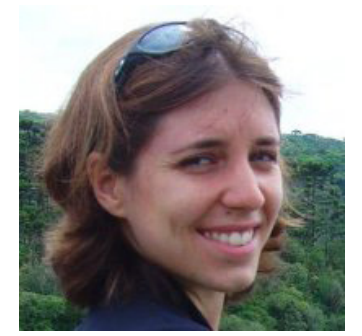

Recebido em: 16/6/2016

Aceito em: 7/7/2016

Endereço do autor:

Ariane Diniz Holzbach <arianeh@id.uff.br>

Instituto de Arte e Comunicação Social - Universidade Federal Fluminense

Rua Lara Vilela, 126 - São Domingos

24210-590 - Niterói - RJ - Brasil 